\title{
A Letter on Belt Conveyor System as a Mode of Transportation in Industry
}

\author{
Monideepa Pati ${ }^{1}$, Ujjayan Majumdar ${ }^{2 *}$ \\ ${ }^{I}$ Student, MBA-PS Transportation Management, Indian Institute of Social Welfare and Business Management, \\ Kolkata, India \\ ${ }^{2}$ Research Assistant, Department of Mechanical and Aerospace Engineering, The State University of New York \\ at Buffalo, Buffalo, United States of America \\ *Corresponding author: umajumda@gmail.com
}

\begin{abstract}
In any power plant coal obtained from the open pit mines should be transported to the plant for the production of power. Many means of transportations are available like truck, railways pipelines, Conveyor belts etc. For Industrial purpose material handling equipment are designed in a way such that material handling is easy, fast, less maintenance cost for the equipment, efficient, safe etc. This paper discusses how conveyor belt is a better mode of transportation in power plants than any other modes available. Provided with brief Discussion various parts of the conveyor belt, and also about some types of conveyor belts used in Power plants. There are many types of conveyer belts present that can be used as per the need of different power plants. Also provided with a proper safety design values for the safe and efficient working of the belt.
\end{abstract}

Keywords: Belt conveyor system, Idlers, Supply of materials, Transportation.

\section{Introduction}

Coals obtained from open pit mines should be moved to thermal power plants for Production of power. Very large amount of coal is required for Production of power in thermal power plants. This coal is transported by various modes of Transportation by considering both technical Parameters and the cost of the particular mode of Transportation. Selecting any of the modes of transportation process depends upon some of the factors like transportation distance, inclination of the road, amount of coal needed to be transported, investment cost, production capacity and unit production cost of the coal mine, it also depends upon the Physical properties of the coal like density, humidity, size of the particles etc. The Common alternative mode of transportation in this process are trucks, railways, Pipelines, and Conveyer belt is one of them.

Though conveyer belt needs higher investment cost compared to an important mode of transportation used in industries i.e. Truck. But Conveyer belt have a lower operating cost and for the shorter distance of transportation conveyer belt is much better than truck and along with that Conveyer belt operation is continuous. Conveyer belt can be used to transport both bulk and unit loads. In present days as the mines are getting deeper conveyer belt is more preferred.
In today's scenario conveyer belt is been used as a mode of transportation to transport bulk material for a long distance because of the economy and the safety of the operation reliability, versatility, and practically unlimited ranges of capacities. Conveyer belt can perform many other processing functions between its usual work of continuous supply of material between two nodes. Low labor and low energy requirements are fundamental with belt conveyors as compared with other means of transportation [11].

The increased dependence of these industries on belt conveyors is primarily because of the fact that they have had 'everything going for them' [12]. Relatively lesser operation cost, labor cost, and lesser energy requirement enhances the demand for Conveyer belt. The mechanical parts such as idlers, drive machinery, pulleys, and many other accessories, have undergone development to improve durability and performance. As rubber belts are highly resistant to corrosion and abrasion, maintenance costs are Comparatively low during handling highly corrosive material or those that are extremely abrasive. Some Material causes sticking and packing on using other mode of transportation are handled properly on conveyer belt.

Conveyer belt avoids the delay, confusion and safety hazards of other mode of transportation used for the continuous and smooth supply of coal and other materials in power plant.

Conveyer belt occupies much lesser area and also decreases the cost of constructions required for other mode of transport like rail lines or proper road for trucks along with that lesser man power is needed for its operations. Such structures are economical and are adaptable to special requirements. It can be modified to a structure that can prevent pollution as well as can protect weather [12].

Along with that Conveyer belt takes comparatively less time for the transportation of the required material.

Conveyer belt: Conveyer belt is a mechanically handled appliance mostly used to transport material from one place to another. Conveyer belt is mainly used to transport bulky materials specially in Industries or for industrial purpose. It also led to the efficient, quick and easy transportation for both heavy 
and light materials to the desired location as per need. Conveyor systems are durable and reliable in materials transportation and warehousing. Along with power industries conveyer belt is used in many other industries like Steel, automotive, electronics, Pharmaceuticals etc. [1].

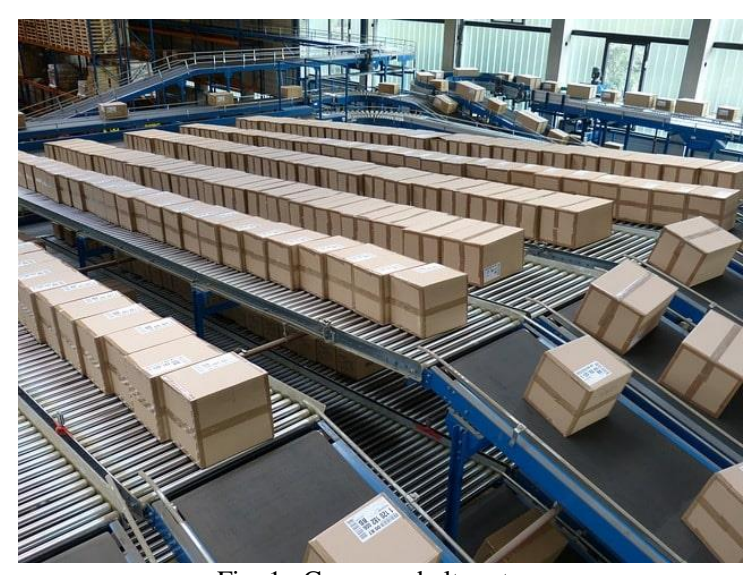

Fig. 1. Conveyer belt system

Factors leading to the widespread use of conveyer belts in Industries:

a) Conveyer belts can Transport high quantity of materials of various shapes and sizes.

b) Can be installed in most situations while usually being able to add value and increase the safety of the workplace due to automation and safeguards.

c) There are many options available to run the conveyer belt system such as mechanical hydraulic and fully automated systems.

d) Maintenance cost of conveyer belt is lower than other mode of transport facility available to be used in Industries.

e) The advanced safety features prevent accidents and injuries through the system.

f) Conveyer belts can be installed everywhere and are much safer than using a forklift or other machine to move materials.

g) Less labour power is needed for this mode of transportation.

h) Less place is needed for installation as it can be made overhead.

Based on the Principle of Operations many types of conveyer systems are available like gravity, belt, screw, bucket, vibrating, pneumatic/hydraulic, chain, spiral, grain conveyor systems etc. [8].

They are used as per the need of different industries. Choice of the proper mode of transportations depends on various factors like: Size and weight of material to be transported, Distance of transportation, height to which the material is needed to be transported, Volume of the material to be transported. Some section of the industries where conveyer belt is essentially need are like Transportation, sorting, accumulation and the point where weights are needed to be loaded or putdown [9].

A belt conveyor consists of an endless and flexible belt of high strength with two end pulleys (driver and driven) at fixed positions supported by rollers. In this work, 3 roll idlers are required for adequate support of materials transported and protection of the belt along its length. Pulleys are used for providing the drive to the belt through a drive unit gear box powered by an electric motor. It also helps in maintaining the proper tension to the belt. The drive imparts power to one or more pulleys to move the belt and its loads [6].

Materials are transported over the required distance as a result of friction generated between the roller surface and the moving belt set in motion by a rotating pulley (drive pulley). The other pulley (driven or idler pulley) acts as a wheel around which the material rotates and returns in a continuous process. Continuous processes are characterized by non-stop motion of bulk or unit loads along a path without halt for loading and unloading.

Important parts of the Conveyer belts are [2]:

a) Belts

b) Motors

c) Gear box

d) Pulleys

Different types of Pulleys used in a conveyor belt system are:

- Drive pully

- Tail pulley

- Snub pulley

- Bend pully

- Take up pulley

e) Idlers (Rollers which carries the belt)

Different types of Idlers that are used in a Conveyor belts are [7]:

- Carrying Idlers

- Return Idlers

- Impact Idlers

- Transition Idlers

f) Loading a conveyer belt. (Chute, Transfer conveyor, Vibratory feeder).

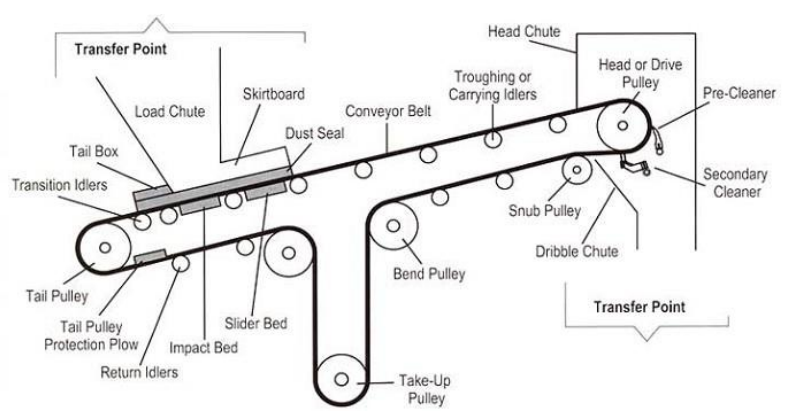

Fig. 2. Parts of the conveyor belt

a) Belt: The belt is consisting of 2 or more layers of Materials. There are several materials that can be used to make conveyor belts from PVC to rubber material. Belts is used to transport materials from one location to another location. This 
belt should transport both moderately and abrasive material like coal, coke, cement etc. Some of the properties required for the belt to work as a transportation system in industries are [3]:

- High wear resistance.

- Small elongation at highest working tension.

- High impact resistance.

- Excellent directional stability.

- Good trough ability.

- Good weather resistance.

- Not susceptible to humidity and microorganisms.

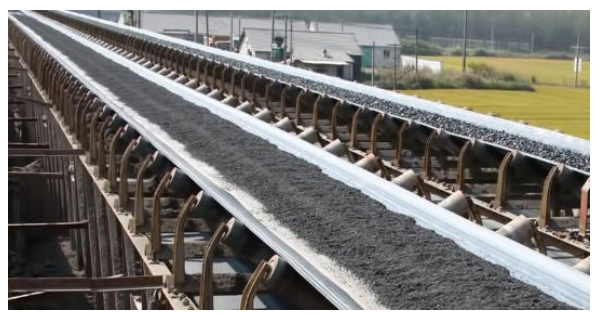

Fig. 3. Belts

b) Motor: Huge load is driven by the conveyor belt so the motor will need very high starting torque greater that their running torque. Now-a-days for the Conveyor belt system 3phase induction motors is used so that the starting current is very low and along with that starting torque is very high.

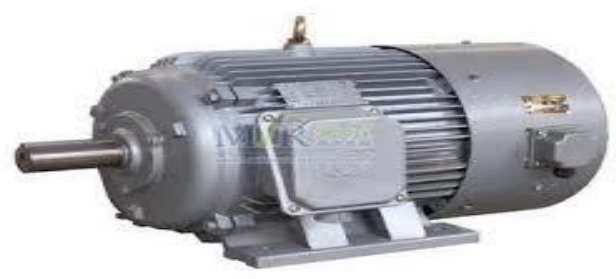

Fig. 4. Motor for continuous power supply [10]

c) Gear box: Industrial gearbox are used to reduce speed to slow down conveyor belts by adjusting engine torque. Gearbox converts speed to torque or vice versa and transmit this load to the conveyer belt via its output shaft.

d) Pulleys: In Conveyer belt systems pullies are designed as a means to drive, redirect, provide tension and to track the conveyor belt. Types of pullies used in a conveyor system are:

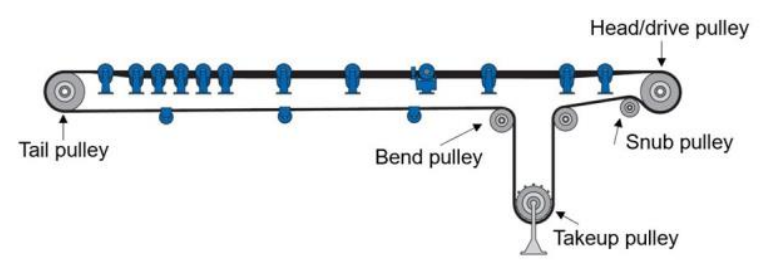

Fig. 5. Pulley

- Head or Drive pulley: Drive Pulley is located at the discharge terminus of the Conveyor. It is mainly used for the purpose of driving the conveyor belt and often has a larger diameter than other Pullies. Typically mounted in external bearings and driven by an external drive source. For better traction it is usually lagged by rubber or other ceramic materials.

- Tail end pulley: Tail pulley is located at the loading end of the belt. It is used to redirect the conveyor belt back to the drive pulley. It can use internal bearing or can be mounted on external bearings. Tail pulley serves the purpose of take up pulley on a shorter conveyor.

- Snub pulley: It is used to improve the traction of the head pulley by increasing the angle of the wrapped belt.

- Bend pulley: It is used to change the direction of the belt added at the return portion of the conveyor belt. Belt bends over it to form a loop for the take up pulley to maintain the tension of the belt.

- Take up Pulley: It is basically used to maintain the tension of the belt; its length can be varied when required. Even if some part of the belt gets destroyed it can be compensated by varying the length of the take up pulley. To maintain the tension a weight is being attached at down of this pulley [13].

e) Idlers: They are cylindrical shaped bar that move along and under the conveyer belt. Idlers supports the impact and weight of the material being transferred through the belt. There are many types of idlers used in all through the conveyer belt depending on the functions and the need of it. It is used in conveyor belt for easy safe and continuous delivery to material to the locations [15].

Different types of idler used in conveyor belts are [14]:

- Carrying Idlers: Used for carrying huge materials and manufactured mostly at an angle of 20,35, 45 degrees. Self-aligned carrying idlers can change the angle of inclination to maintain a proper cross section area through throughout the belt carrying material so that the materials loaded did not fall along the way to the tail pulley. Carrying idlers may consist of either 3 or 5 rollers.

- Return Idlers: Return idlers are needed to only support the mass and impacts of the empty belt returning after the unloading of material. It mostly has one or two rollers set for the safe movement of the returning belt. For this type of idlers one roller is more prevalent.

- Impact Idlers: Impact idlers are installed under the belt over the full loading length, it is installed to provide support to the belt and are located typically at an interval of $350 \mathrm{~mm}$ to $450 \mathrm{~mm}$. The cushioning ability of the impact idler absorb most of the energy associated during loading the conveyor belt.

- Transition Idlers: This type of pulley is found either at the end or at the head side of the conveyor belt. These rollers set comprises of idler rolls along with the base 
these rollers are fitted it also consist of small angle inclination like the rest of the rollers. The no of transition idlers depends upon the trough angle of the conveyor belt.

g) Loading a conveyor belt

- Chute: conveyor chutes are used in bulk handling to perform a variety of operation. In particular, the loading of a belt conveyor, and the transfer of material from one moving belt conveyor to another, are important tasks.

- Transfer Conveyor: Transfer conveyor is used to transfer materials from one conveyor system to other.

- Vibratory feeder

Safety Designs: There has been several safety designs proposed by Majumdar et. al., [8], [18]. One such design is of the belt conveyor system and how can we attend safety in the system. Below is an image provided with some safety analysis of the Belt conveyor system with the idlers. Consisting diagram consists of the analysis of the equivalent stress and elastic strain failure which has been avoided well in the same.
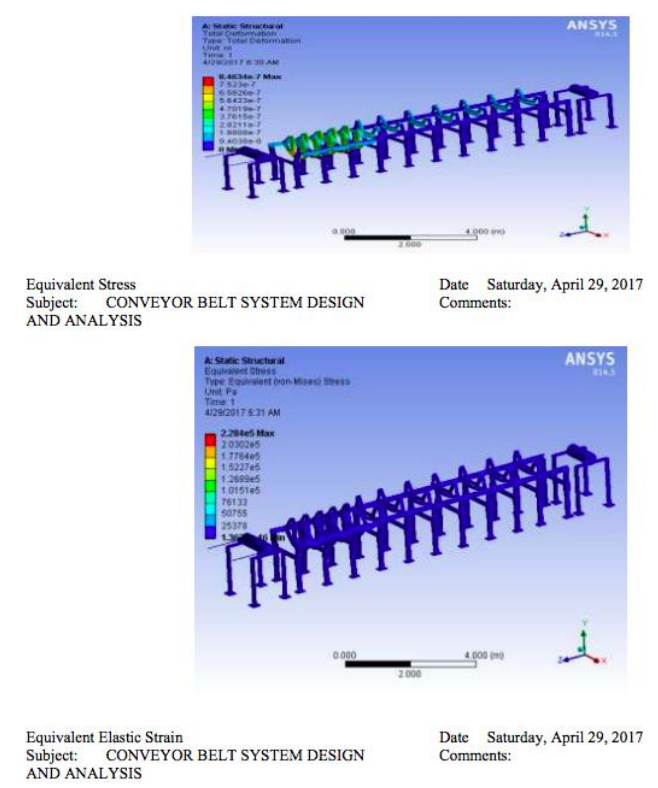

Fig. 6. Conveyor belt system design and analysis

Some types of Pullies used in power industries [4]:

a) Belt Conveyors: It helps to transport large volume of coal over a long distance. They come with a long rubber, balata or canvas belt running over head and tail pullies supported by idlers at regular interval. This type of conveyer belt can successfully carry loads on an inclination of 20 degrees to the horizontal land and can carry between $50-100$ tones per hour [5].

This type of conveyer belt requires very less maintenance and repair, along with that it is highly economical and the power consumption is low. Its speed can be varied depending upon the need. Along with all these advantages it has a disadvantage of poor performance over short distance [16]. b) Bucket Conveyor: The bucket conveyor contains buckets attached to a chain that moves over two wheels, making it extremely useful in vertical lifts. The buckets carry the coal at the bottom and discharge it at the top. The bucket conveyor elevator limits transfers to 30 -meters vertically, with a maximum horizontal inclination of up to 60 degrees.

c) Skip Hoist Conveyor: This type of conveyer systems is available in different type of construction patterns like double track tilting bucket discharge and single-track bottom discharge to suits different power plant needs. The drive units allow it to be installed at the top intermediate or bottom level.

The factors because of that influences to have it for power plants are the load capacity, expected high turnover, less operation cost and maintenance.

d) Grab Bucket Conveyor: This type of conveyer system allows to lift coal from one point to another. It mostly uses tower or crane to transfer coal with a 3 cubic meter bucket operating over a distance of 60 meters and can carry coal up to 100 tons of coal per hour.

e) Screw Conveyor: Screw conveyors come with a fitted endless helicoid screw and a driving mechanism connected to one end of the shaft; the other end of the shaft is often enclosed with a ball bearing. The system transfers coals from one end to the other when the screw rotates. Depending on your transfer capacity, you can use screws with a diameter of $15 \mathrm{~cm}$ to $50 \mathrm{~cm}$, and vary the speeds from 70 to $120 \mathrm{rpm}$.

f) Flight Conveyor: This type of Conveyor works best with coal transfers that need the fitting of several storage bins located below the conveyors, the steel scrappers attach two or more chains, The Scrappers discharges the coal at the bottom by scrapping the coal through a trough.

All though there are several maintenance and repair options available but it becomes costly with times. Scrappers may cause wear and tear along with that the dragging of coal by the scrappers also causes high power consumption [17].

\section{Discussion and Conclusion}

There are many transportation modes used in industries like truck, pipelines, airways, conveyor belts. Conveyor belt can be considered as a best mode among these because of the following essential factors which are needed for safe and efficient transportation. Conveyor belts and trucks are the important mode of transportation used in industries, according to the study it is known that conveyor belt is much safer than truck as it is noted in 2017 that half of the fatal accidents are vehicle related on the mines as heavy loaded trucks are used there, requires less maintenance cost as compared to the other mode. Conveyor belt can be so long to cover the whole area of the industries. Less labor force is needed in case of conveyor belt [18].

Life expectation of the conveyor belt is much more than that of other mode of transportation. Conveyor belts can follow where tracks can [19].

Power consumption for coal is much lower than other 
conveyors. It remains flexible in almost all weather by an easy installation of overhead covers. For coal handling, it is best to install the equipment up to an inclination up to 20 degrees to the horizontal.

Unlike power plant Different types of conveyor belts are used in different industries like food industries, Retail, Automation etc. Therefore, as the demand increases sells also increases year by year which is shown by the graph provided below [20].

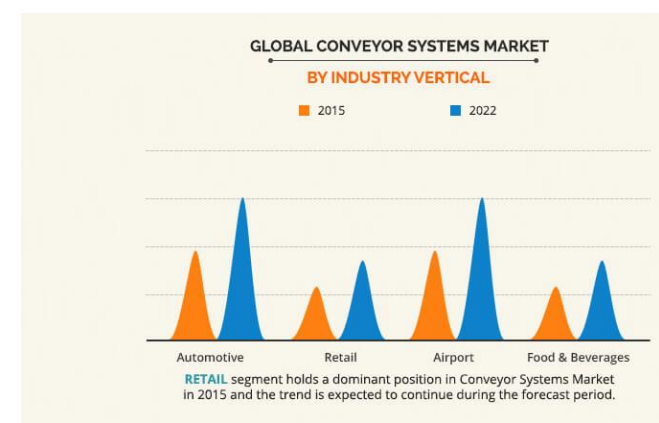

Fig. 7. Global conveyor systems market

\section{References}

[1] "What is a Conveyor System? Applications, Uses, And Types Explained." L.A.C. Conveyors \& Automation, 18 Mar. 2020, https://www.lacconveyors.co.uk/what-is-a-conveyor-system/.

[2] Understanding Conveyor Systems - Types, Applications and Considerations. https://www.thomasnet.com/articles/materials-handling/understandingconveyor-systems. Accessed 18 Dec. 2020.

[3] "How Do Conveyor Belts Work?, Belt Functions, Uses \& Applications." SEMCOR, 20 Aug. 2019. https://www.semcor.net/blog/how-do-conveyor-belts-work/.

[4] Benefits of Using Conveyor Systems in Different Industries, https://www.norcalcompactors.net/benefits-of-using-conveyor-systemsin-different-industries/. Accessed 18 Dec. 2020.

[5] "How Do Conveyor Belts Work?, Belt Functions, Uses \& Applications." SEMCOR, 20 Aug. 2019.

https://www.semcor.net/blog/how-do-conveyor-belts-work/.
[6] "Report of the Research Committee for Material Handing and Transport Machine," Journal of the Society of Mechanical Engineers, vol. 73, no. 619, 1970, p. 1112.

[7] "What is a Conveyor System? Applications, Uses, And Types Explained." L.A.C. Conveyors \& Automation, 18 Mar. 2020, https://www.lacconveyors.co.uk/what-is-a-conveyor-system/.

[8] Majumdar, Ujjayan, et al., "Design and Analysis of a Belt Conveyor System," in Sch. J. Eng. Tech., vol. 6, no. 7, pp. 212-30, July 2018.

[9] "Conveyor System - Conveyor Belt Manufacturer - Jagruti Rubber." Conveyor system, http://www.conveyorsystemmanufacturer.com/. Accessed 18 Dec. 2020.

[10] David, "Metallurgist \& Mineral Processing Engineer," in Metallurgist \& Mineral Processing Engineer, https://www.911metallurgist.com/. Accessed 18 Dec. 2020.

[11] NSHM Knowledge Campus. Troughed Belt Conveyor \& Flat Belt Conveyor. https://www.slideshare.net/shantanudut/troughed-belt-conveyor-flatbelt-conveyor-18114525. Accessed 18 Dec. 2020.

[12] Belt Conveyors for Movement of Bulk Materials - IspatGuru. https://www.ispatguru.com/belt-conveyors-for-movement-of-bulkmaterials/. Accessed 18 Dec. 2020.

[13] J. F. Richardson, J. H. Harker, and J. R. Backhurst, "Particle Technology and Separation Process," Chemical Engineering, vol., 2, 5th Edition, Elsevier publisher, New Delhi, India. pp. 29-35, 2002.

[14] I. A. Daniyan, A. O. Adeodu, and O. M. Dada, "Design of a Material Handling Equipment: Belt Conveyor System for Crushed Limestone Using 3 roll Idlers," vol. 1, no. 1, pp. 1-7, 2014.

[15] Fertilizing Corn in Minnesota. https://extension.umn.edu/crop-specificneeds/fertilizing-corn-minnesota. Accessed 18 Dec. 2020.

[16] Types of Conveyors in a Thermal Power Plant. https://blog.swantonweld.com/types-of-conveyors-in-a-thermal-powerplant. Accessed 18 Dec. 2020.

[17] Coal Handling Systems \& Coal Mining Belt Conveyors, Montague Legacy Group. http://www.montaguelegacygroup.com/coal.html. Accessed 18 Dec. 2020.

[18] M. Ujjayan, and S. Maity, "Design and Analysis of Six Speed Gear Box," in International Journal of Research in Engineering, Science and Management, vol. 1, no. 9, pp. 7-11, Sept. 2018.

[19] Conveyor Pulley Selection Guide. https://www.pcimfg.com/wpcontent/uploads/2014/11/PCI_Pulley_Selection_Guide_2014.pdf.

[20] E. Shevtshenko et al., "Sustainable design of material handling equipment: a win-win approach for manufacturers and customers," in Mechanika, vol. 18, no. 5, pp. 561-568, Nov. 2012. 